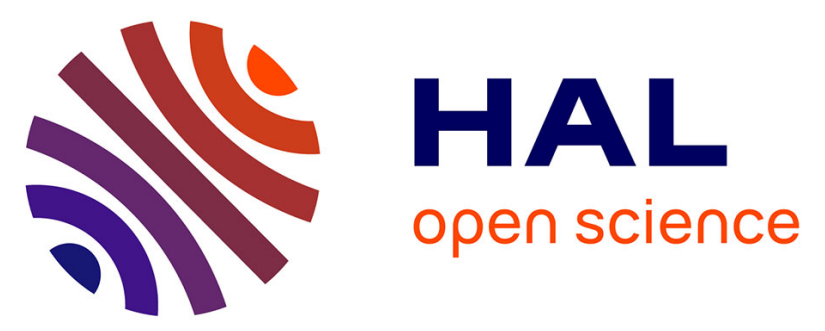

\title{
A TEST OF CHEAP TALK IN DIFFERENT HYPOTHETICAL CONTEXTS: THE CASE OF AIR POLLUTION
}

\author{
Dominique Ami, Frédéric Aprahamian, Olivier Chanel, Stephane Luchini
}

\section{- To cite this version:}

Dominique Ami, Frédéric Aprahamian, Olivier Chanel, Stephane Luchini. A TEST OF CHEAP TALK IN DIFFERENT HYPOTHETICAL CONTEXTS: THE CASE OF AIR POLLUTION. 2009. halshs-00382511

\author{
HAL Id: halshs-00382511 \\ https://shs.hal.science/halshs-00382511
}

Preprint submitted on 7 May 2009

HAL is a multi-disciplinary open access archive for the deposit and dissemination of scientific research documents, whether they are published or not. The documents may come from teaching and research institutions in France or abroad, or from public or private research centers.
L'archive ouverte pluridisciplinaire HAL, est destinée au dépôt et à la diffusion de documents scientifiques de niveau recherche, publiés ou non, émanant des établissements d'enseignement et de recherche français ou étrangers, des laboratoires publics ou privés. 


\title{
GREQAM
}

Document de Travail

Groupement de Recherche en Economie Quantitative d'Aix-Marseille - UMR-CNRS 6579 Ecole des Hautes Etudes en Sciences Sociales Universités d'Aix-Marseille II et III

A TEST OF CHEAP TALK IN DIFFERENT HYPOTHETICAL CONTEXTS: THE CASE OF AIR POLLUTION

\author{
Dominique AMI \\ Frédéric APRAHAMIAN \\ Olivier CHANEL \\ Stéphane LUCHINI
}

January 2009 


\title{
A Test of Cheap Talk in Different Hypothetical Contexts: The Case of Air Pollution
}

\author{
Dominique Ami \\ UNIVERSITÉ DE LA \\ MÉditerRanÉE-IDEP
}

Olivier Chanel

GREQAM-IDEP

CNRS

\author{
Frédéric Aprahamian \\ UNIVERSITÉ \\ DE TOULON-VAR
}

Stéphane Luchini

GREQAM-IDEP

CNRS

\section{January 2009}

\begin{abstract}
We explore the influence of a neutral cheap talk script in three typical scenarios used in the CV literature devoted to the valuation of air pollution effects. We show that cheap talk has a differentiated effect depending on the scenario implemented. It decreases protest responses with no effect on WTP values in the scenario based on a new drug. When a move to a less polluted city is involved, it has no effect on protest responses but decreases WTP values. Surprisingly, cheap talk increases protest responses but decreases WTP values when new regional air pollution regulations are at stake.
\end{abstract}

Keywords: $\quad$ Willingness to pay, contingent valuation, cheap talk, context, field experiment, air pollution

JEL Classification: D6, C9

$\ddagger$ Financial support of French Research Ministry (n04 5666 ACI Santé et Environnement) and technical support from the Provence-Alpes-Côte-d'Azur Regional Council are gratefully acknowledged.

b Corresponding author: Olivier Chanel. GREQAM, 2 rue de la Charité, F-13002 Marseilles, France, e-mail: olivier. chanel@univmed.fr. 


\section{Introduction}

Contingent valuation (CV) studies are increasingly used to estimate the value of non-market goods and services, environmental goods or health care programs in the absence of market prices. They raise methodological as well as practical issues that have been extensively documented (Mitchell and Carson, 1989) and critically assessed (see for instance Hausman, 1993). One major criticism of the CV method has to do with its hypothetical nature, that is, there are no monetary incentives. Because of this, respondents are more likely to misstate their true willingness to pay (WTP), almost always by overstating what they would be willing to pay in real situations - the so-called hypothetical bias (see for instance the meta analyses of List and Gallet, 2001; Little and Berrens, 2004; Ash et al., 2004; or Murphy et al., 2005a). Several calibration methods have been proposed in the literature to counter-balance hypothetical bias, ${ }^{1}$ and one in particular has attracted a lot of attention: the 'cheap talk' technique.

Cheap talk consists in explicitly informing respondents of the existence of the hypothetical bias and asking them to try to avoid it by answering as if they were in a real situation (Cummings, Harrison and Osborne, 1995). ${ }^{2}$ Since Cummings and Taylor's (1999) article, which concluded that the cheap talk script was able to mitigate the hypothetical bias, some thirty published CV studies have tested the cheap talk approach. Some authors confirm the results of Cummings and Taylor (1999), ${ }^{3}$ others have find no cheap talk effect - or even a worsening of the hypothetical bias - depending on the length of the script (Cummings, Harrison and Osborne, 1995; Aadland and Caplan, 2006a; 2006b), the level of the bids used in referenda (Brown et al., 2003; Murphy et al., 2005b, Aadland et al., 2007; Whitehead and Cherry, 2007), the experience / familiarity of respondents with the good valued (List, 2001; Aadland and Caplan, 2003; Lusk, 2003), the nature of the good (for instance, Samnaliev et al., 2003; Carlsson and Martinsson ,2006; Brummett et al., 2007; or Blumenschein et al., 2008 obtain no significant effect with private goods whereas differentiated effects are found in Aadland and Caplan, 2006a, b; Poe et al., 2002; Ajzen et al., 2004; or Bulte et al., 2005 with public goods). 
One avenue has not yet been explored: the interaction between cheap talk and the design of the hypothetical scenario implemented in the CV exercise. This is surprising, because designing accurate scenarios precisely means that stated preferences have to be in line with preferences when monetary incentives are binding, so as to mitigate hypothetical bias. ${ }^{4}$ In this paper, we investigate the interaction between cheap talk and scenario design using a comparative study. We explore the influence of a neutral cheap talk script in three typical scenarios used in the CV literature devoted to the valuation of air pollution effects: a first scenario that presents a new drug that decreases long-term health effects of air pollution, a second scenario that consists of a move to a less polluted city, and a third scenario based on the implementation of new regional air pollution regulations. Half of each subsample is exposed to a cheap talk script. Thus, the three scenarios are used as relative benchmarks to explore potential differentiated effects of a neutral cheap talk script on stated WTP and protest answers.

In order to isolate the interaction between cheap talk and the scenario, we implemented a simultaneous contingent valuation survey that allows for more control of the survey design (see Chanel et al. 2006). We show that cheap talk has a differentiated effect depending on the scenario implemented. It decreases protest responses with no effect on WTP values in the scenario based on a new drug. When a move to a less polluted city is involved, it has no effect on protest responses but decreases WTP values. Surprisingly, cheap talk increases protest responses but decreases WTP values when new regional air pollution regulations are at stake.

The remainder of this paper is organized as follows. Section 2 describes the data and the experimental design. Section 3 presents the empirical results and section 4 concludes.

\section{Experimental design}

The experiment is a $2 \times 3$ design to investigate the impact of cheap talk on valuation when eliciting subjects' WTP for the same environmental amenity but using different contextual framings. Experimental conditions involve being exposed (or 
not) to a cheap talk script before the valuation exercise starts and three different scenarios that essentially differ in the scope of their beneficiaries.

The aim of the field experiment is to elicit WTP for a decrease in air-pollutionrelated health effects. To do so, we used three typical scenarios from the CV literature devoted to the valuation of air pollution effects. The first scenario adopted the methodology proposed by Alberini et al. (2004) and Krupnick et al. (2002). The scenario asked subjects how much they would be willing to pay for a new drug, to be taken on a monthly basis, that would reduce by half the long-term health effects of air pollution exposure, hereafter called Drug scenario (see Appendix A for the hypothetical scenario). ${ }^{5}$ The second scenario, hereafter called Move scenario, asks the subject his/her willingness to pay for moving with his/her household between two cities, which are exactly the same (city size, housing, weather, public services etc.) with the exception of the cost of living and the level of air pollution (Viscusi et al., 1988; Chanel et al., 2006 -see Appendix B for the hypothetical scenario). ${ }^{6}$ We borrowed the third scenario, hereafter called Regulation scenario, from the New Energy Externalities Developments for Sustanability project (NEEDS) supported by the European Commission (Desaigues et al. 2007). It involves new rules and laws applied to polluting firms and activities (industries, transport, etc.). Since their implementation would increase the cost of living, through market prices, the subject is asked the maximum amount $\mathrm{s} /$ he would be willing to pay each month to implement this policy (see Appendix $\mathrm{C}$ for the hypothetical scenario). ${ }^{7}$ Note that the change in the morbidity and mortality risks of air pollution presented in each scenario are identical ("half less"). The concept of reducing air pollution health effects by half was progressively explained to subjects (see below) and based on epidemiological data (see Künzli et al., 2000). It is also worth noting that the payment vehicle is similar in all three scenarios: an increase in private expenditure.

We now present the cheap talk script used in the experiment, which can be described as neutral and light (see appendix D for the script):

- The script can be considered as neutral (as opposed to positive). A positive script states that the hypothetical bias leads to an overstating of real WTP. 
A neutral script either indicates to subjects the existence of the hypothetical bias without indicating its direction or indicates that, in a hypothetical situation, subjects tend to over or understate their WTP as well as giving protest answers. We chose the latter alternative.

- The script is light (as opposed to heavy) since no quantitative information on the size of the hypothetical bias is provided to the subjects. In a heavy version, the script gives precise numbers for the hypothetical bias. For instance, Cummings and Taylor (1999) indicate to subjects that "on average, [...] 38 percent of them voted "yes" [in the hypothetical situation whereas] 25 percent voted "yes" [in the real situation]" (p. 651).

As we had found no published articles quantifying hypothetical bias on French data, we kept to a neutral and light version. ${ }^{8}$

The experiment was implemented in October 2006 in Marseilles (0.83 million inhabitants), the second largest city in France and the largest city of the Bouches-duRhône (BDR) district (1.9 million inhabitants). Subjects were recruited through advertisements in local newspapers and regional TV news - the survey was described as being about quality of life. Each participant was remunerated $€ 20$ using gift vouchers. Subjects were unaware of the exact topic of the survey prior to the experiment. The experiment was conducted in the Regional Council voting room, equipped with an electronic voting system allowing information on WTP to be collected real time for up to 120 participants. Thus, all subjects in each session completed their tasks simultaneously and full anonymity was maintained (even to the research team). Full anonymity is vital, since List et al. (2004) for instance have found that direct social interactions may affect WTP for a public good. Six sessions took place over two days. Each session was devoted to one particular scenario (scenarios were drawn randomly) and cheap talk was randomly implemented or not. Thus, at the end of the two days, we had 6 sessions testing all possible combinations.

The CV experiment itself is divided into three parts. The first part contains a self-administered survey with questions on the socioeconomic background of the 
subject and knowledge of air pollution. In particular three questions are devoted to subjects' experience of pollution, as in Lusk (2003): (1) self-reported knowledge of air pollution, and whether the subject knows (2) the national official scale of air pollution levels (Atmo) and (3) the local air pollution index (Airmaraix). Thereafter, the elicitation procedure begins. If the session is drawn as a cheap talk session, a script is read aloud and presented to subjects on the main screen of the voting room (as well as on individual screens) just after the scenario is presented. Once the cheap talk script has been presented, the valuation exercise starts. Subjects are asked, using an electronic voting system followed by an openended question, their WTP for reducing air pollution health effects by half.

Participants could register using the Public Economics Institute web site or a dedicated phone line. As registration was not mandatory, the total number of participants in each session varies (see Table 1). More than $75 \%$ of subjects live in Marseilles and there are more women in our sample than in BDR population (65.05 versus $52.10, p<.001)$. Our sample is also younger, with $53 \%$ under 40 as opposed to $33 \%$ in $\mathrm{BDR}$, and $1 \%$ over 75 as opposed to $19 \%$ in the general population. Household size appears to be the same as in the BDR (2.51 versus $2.3, p=.27$ ). There is no significant difference between monthly mean income in our sample and monthly mean income in the BDR population (1,516 versus 1,536 euros $p=.80$ ) and there is no significant difference for median income (1,250 versus 1,294, 95\% Confident Interval $[1,200,1,300])$. However, analysis of the 25 th percentile suggests that subjects tend to be poorer than in the general BDR population. (610 euros versus 900; 95\% Confident Interval [547, 750]. We investigate the impact of cheap talk on WTP in the different scenarios in the next section.

\section{Results}

\section{Unconditional cheap-talk effects}

i) Number of protest responses. ${ }^{9}$ Table 1 presents different rates of protest responses depending on the experimental session considered. Under standard conditions (i.e. no cheap talk), the protest response rate for the Drug scenario (16\%) 


\begin{tabular}{llcc|c}
\hline \hline Scenario & & Standard & Cheap Talk & All sessions \\
\hline Drug & $\sharp$ of subjects & 49 & 60 & 109 \\
& $\sharp$ of protests (rate) & $8(16 \%)$ & $5(8.3 \%)$ & $13(11.9 \%)$ \\
Move & $\sharp$ of subjects & 86 & 43 & 129 \\
& $\sharp$ of protests (rate) & $3(3.5 \%)$ & $1(2.32 \%)$ & $4(3.1 \%)$ \\
Regulation & $\sharp$ of subjects & 63 & 71 & 134 \\
& $\sharp$ of protests (rate) & $2(3.2 \%)$ & $11(15.5 \%)$ & $13(9.7 \%)$ \\
\hline All scenarios & $\sharp$ of subjects & 198 & 174 & 372 \\
& $\sharp$ of protests (rate) & $13(6.5 \%)$ & $17(9.8 \%)$ & $30(8.1 \%)$ \\
\hline \hline
\end{tabular}

Table 1: Summary of statistics on protests by experimental session and scenario.

largely exceeds those for the Move scenario $(3.5 \%-p=.011)$ and for the Regulation scenario $(3.2 \%-p=.018)$. There are no significant differences between the Move and Regulation scenarios under standard conditions $(p=.999)$. Cheap talk has a different impact for each scenario. It decreases (but not significantly) the protest response rate in the Drug scenario from $16 \%$ to $8.3 \%(p=.163)$. It has no visible impact in the Move scenario, where it moves from $3.5 \%$ to $2.3 \%(p=0.500)$. In the Regulation scenario, cheap talk has a positive and significant effect on the rate of protest responses (from $3.2 \%$ to $15.5 \%$ with $p=.017$ ) and thus reverses the ranking of the Regulation and Drug scenarios on protest responses (although non-significantly, $p=0.327$ ). Overall, the protest response rate appears to be relatively low (between $6.5 \%$ and $9.8 \%$ ) and the average impact of cheap talk on protest response rate is statistically non-significant $(p=.346)$.

ii) WTP statistics. Table 2 shows that mean WTP first differs depending on which scenario has been used. The mean WTP obtained in the Move scenario, taking standard conditions and cheap talk conditions together $(€ 80.15)$ is significantly and substantially higher than in the Drug $(€ 22.83$ with $p<.001)$ and the Regulation $(€ 18.15$ with $p<0.001)$ scenarios. There are no significant differences between mean WTP for the Drug and Regulation scenarios ( $p=0.263$ ). Second, the impact of cheap talk is qualitatively the same whatever the scenario considered: a decrease in mean WTP. On average, the mean WTP significantly decreases from $€ 52.81$ to $€ 27.60(48 \%-p<0.001)$. However, this decrease is not significant in the Drug $(p=0.268)$ and Move $(p=.167)$ scenarios, while the $40 \%$ 


\begin{tabular}{llcc|c}
\hline \hline Scenario & & Standard & Cheap Talk & All sessions \\
\hline Drug & $\sharp$ of subjects & 49 & 60 & 109 \\
& Mean WTP $(\mathrm{sd})$ & $€ 27.26(50.4)$ & $€ 19.22(21.9)$ & $€ 22.83(37.5)$ \\
& Mean WTP/Income & $4.48 \%$ & $1.86 \%$ & $3.04 \%$ \\
Move & $\sharp$ of subjects & 86 & 43 & 129 \\
& Mean WTP & $€ 89.29(113.5)$ & $€ 61.86(86.7)$ & $€ 80.15(105.8)$ \\
& Mean WTP/Income & $7.96 \%$ & $8.96 \%$ & $8.29 \%$ \\
Regulation & $\sharp$ of subjects & 63 & 71 & 134 \\
& Mean WTP & $€ 22.89(28.9)$ & $€ 13.94(23.5)$ & $€ 18.15(26.5)$ \\
& Mean WTP/Income & 2.61 & $1.06 \%$ & $1.78 \%$ \\
\hline All scenarios & $\sharp$ of subjects & 198 & 174 & 372 \\
& Mean WTP (sd) & $€ 52.81(86.4)$ & $€ 27.60(51.0)$ & $€ 41.02(73.1)$ \\
& Mean WTP/Income & $5.42 \%$ & $3.25 \%$ & $4.41 \%$ \\
\hline \hline
\end{tabular}

Table 2: Summary of statistics on WTP by experimental session and scenario.

drop in mean WTP is significant in the Regulation scenario $(p=0.050)$. We then take subject's income and compute in the mean of WTP divided by income. The overall effect of cheap talk on WTP when income is considered is less salient and less significant $-p=.0763$ (this is also true for all scenarios with $p$-values .276 , .726 and .001 respectively for the Drug, Move and Regulation scenarios).

\section{Conditional cheap-talk effects}

We have so far considered only differences in mean WTP or only taken into account subject's income when testing differences in mean. This latter normalization may however be too rough and we therefore need to confirm the primary findings on the effects of cheap talk in a more systematic way, by taking into account subjects' heterogeneity. We do so by first estimating a Heckman selection model (Heckman, 1979): (1) a participation equation accounting for whether or not the subject agrees to participate in the valuation exercise, i.e. subject does not give a protest response and (2) a WTP equation for subjects who actually state a WTP value. Since the Likelihood Ratio test cannot reject the null of independence between the two statistical processes ( $\mathrm{LR}=1.04$ with $p=.308$ ), we maintain two independent estimations in the following. ${ }^{10}$

Table 3 presents the parameter estimates and their corresponding $p$-values 


\begin{tabular}{rrr}
\hline \hline Variable & $\begin{array}{c}\text { Estimated } \\
\text { parameter }\end{array}$ & $p$-value \\
\hline Individual characteristics & \\
Constant & 1.395 & 0.002 \\
Age & -.0137 & 0.069 \\
EnvPresAss & -.6189 & 0.006 \\
FreshAir & .4918 & 0.054 \\
\hline Move & 1.001 & 0.005 \\
Regulation & 1.091 & 0.009 \\
\hline Scenario effects & \\
Cheap talk effects & .577 & 0.081 \\
Drug $\times$ cheap talk & .396 & 0.494 \\
Move $\times$ cheap talk & -.926 & 0.019 \\
Regulation $\times$ cheap talk &
\end{tabular}

Table 3: Probit equation $(N=360)$

of the Probit model (dependent variable is one if the subject does not protest in the valuation exercise). ${ }^{11}$ Among the explanatory variables tested, Age of the subject (Age), Subject belongs to an environmental preservation association (EnvPresAss) and Subject occasionally or regularly goes to the countryside to breathe fresh air (FreshAir) are found significant (see appendix E for a description of the explanatory variables). The older the subject the less $\mathrm{s} /$ he agrees to participate in the valuation exercise. Belonging to an environmental preservation association increases the probability of a protest response while going to the countryside to breathe fresh air increases willingness to participate in the valuation exercise. Coefficients estimated for the scenario effect as well as for the cheap talk effect confirm unconditional results. The Move and Regulation scenarios lead to significantly less protest responses ( $p=.005$ and .009 ) than the Drug scenario (used as the referent). This conditional effect of the Cheap Talk script confirms the differing results shown in Table 1: it decreases the likelihood of a protest response in the Drug $($ Drug $\times$ Cheap talk, $\mathrm{p}=.081)$ and Move scenarios $($ Move $\times$ Cheap talk, although non-significantly: $p=.494$ ), but significantly increases the likelihood of a protest response in the Regulation scenario (Regulation $\times$ Cheap Talk, $p=.019$ ). 
Table 4 presents the parameter estimates and the $p$-value of the WTP (in logarithm) equation. ${ }^{12}$ First, it is worth noting that the level of the subject's income (in logarithm) is highly significant $(p=.005)$ and positively related to the logarithm of WTP, which is reassuring and provides evidence of the validity of the method (Bishop and Woodward, 1995). Other explanatory variables are found significant: subjects who have a University degree (UnivEdu, < 0.001) and private health insurance (PrivIns, $p=.069$ ) are more likely to state higher WTP. Subjects who never sort their waste (NevSortWaste) are more likely to state lower WTP values $(p=.041)$. Note that the three variables that account for the experience of subjects are not significant: declaring a good knowledge of air pollution (KnowPol), knowing the local air pollution index (KnowAirmaraix) and knowing the official scale of air pollution that is published in the local and national media (KnowAtmo).

The highly significant coefficient associated with the Move scenario $(\mathrm{p}<.001)$ and the positive but non-significant coefficient of the Regulation scenario confirm the results in Table 2: the Drug (referent) and Regulation scenarios lead to very significantly lower WTP on average than the Move scenario. The percentage changes in WTP values induced by the Move and Regulation scenarios with respect to WTP elicited in the drug scenario (referent) are $+227.2 \%$ and $+13.9 \%{ }^{13}$

We now consider the effect of the cheap talk script in the different scenarios. In the Drug scenario, the use of the cheap talk script does not significantly influence subjects' answers compared to the sessions without cheap talk $(p=.725)$. This is not true for the Move and Regulation scenarios: a significant decrease in WTP is obtained when subjects are in the cheap talk session $(p=.048$ and .001 respectively). The percentage changes in WTP values induced by the petition in the Drug, Move and Regulation scenarios are $-21.3 \%,-45.8 \%$ and $-54.5 \%$ respectively.

Finally, because it has been shown that cheap talk fails to remove hypothetical bias for experienced subjects (List, 2001), we investigate whether the effect of cheap talk on subjects varies with experience on air pollution. We do so as in Lusk (2003) through the experience variables defined above. The additional cross effects of cheap talk and experience variables are not significant, whether taking self-reported 
degree of knowledge of air pollution problems (KnowPol, $p=.382$ ), knowing the existing official scale (KnowAtmo, $p=.501$ ) or knowing the local air pollution index (KnowAirmaraix, $p=.851$ ). This absence of effect regarding experience variables may mask differentiated effects of cheap talk that would depend on the scenario. In order to rule out this possibility, we compute the corresponding joint nullity Wald test, which cannot reject the null of no cross effects $(p=.950)$.

\section{Conclusion}

Our findings on the effect of cheap talk in different hypothetical scenarios are mixed. First, we found that cheap talk has the expected effect on WTP values in the Move and Regulation scenarios. It decreases WTP values most sharply in the Regulation scenario. It has, however, no significant effect in the Drug scenario. Cheap talk therefore has a differentiated effect on WTP values in our setting, depending on the hypothetical scenario implemented, with a greater effect when the scenario implies a greater role for future public intervention (Regulation).

Second, cheap talk has an undetermined effect on protest responses. It decreases protest responses in the Drug scenario but it increases protest responses in the Regulation scenario, with no effect in the Move scenario. The cheap talk script states that the hypothetical nature of the exercise can lead subjects to give protest responses. On the one hand, this may lead subjects who may have been unaware of this possibility to take advantage of this opportunity and protest in the valuation exercise, even though they would not have done so without this prior information. On the other hand, the decrease in protest responses could be due to subjects who initially consider protesting in the valuation exercise, but actually refrain from doing so. Aadland and Caplan (2006a) expect a decrease in participation rate due to cheap talk and find an increase in participation rate as we find in the Drug scenario. Their neutral cheap talk script does not, however, mention any form of protest response and they do not detect protest responses for those who refused to participate. Protest responses are typically those given by respondents who care about air pollution but who refuse to pay in the hypothetical scenario. In that 
sense, it can be argued that protest responses are not desirable and a cheap talk script should eliminate them, or at least reduce them.

Third, we find no cross-effect of experience/knowledge and cheap talk. Our results therefore contradict those of List (2001) and Lusk (2003): cheap talk can have a persuasive effect on both experienced and inexperienced subjects. We therefore cannot confirm the assumption that experienced and inexperienced subjects have a different "processing mode" when receiving the cheap talk signal (List, 2001). ${ }^{14}$ However, it could be argued that our explanatory variables do not capture sufficiently well whether or not subjects have experience regarding air pollution. Some subjects stating that they possess good knowledge of air pollution and know the official index and scale of air pollution levels may, in reality, be inexperienced subjects. As a consequence, we may not find any significant effect because our "experienced" group actually also contains "inexperienced" subjects. ${ }^{15}$ On the other hand, it is worth remembering that questions related to experience were asked before the valuation exercise (subjects did not yet know that the survey was about air pollution and involved a valuation task). Hence, subjects did not have any particular incentive to behave "strategically" in replying to these questions.

Does examining the effect of cheap talk help us identify which scenario among the three implemented in this paper is the most reliable for eliciting WTP for improvements in air quality? Ideally, one would like to design hypothetical scenarios without hypothetical biases and protest responses in which cheap talk would indeed have no effect on WTP values. Evidence from the Drug and Move scenarios is not fully conclusive: the Drug scenario induces too many protest responses, while cheap talk induces a significant decrease in WTP values in the Move scenario. In our findings, the Regulation scenario is the most sensitive to cheap talk and is therefore the most questionable scenario. 


\section{References}

[1] Aadland, D., and Caplan, A. J. (2003). "Willingness to pay for curbside recycling with detection and mitigation of hypothetical bias." American Journal of Agricultural Economics, 85(2), 492-502.

[2] Aadland, D., and Caplan, A. J. (2006a). "Cheap talk reconsidered: New evidence from CVM." Journal of Economic Behavior and Organization, 60, $562-578$.

[3] Aadland, D., and Caplan, A. J. (2006b). "Curbside Recycling: Waste Resource or Waste of Resources?" Journal of Policy Analysis and Management, $25(4), 855-874$.

[4] Aadland, D., Caplan, A. J. and O. Phillips (2007). "A Bayesian Examination of Information and Uncertainty in Contingent Valuation." Journal of Risk and Uncertainty, 35, 149-178.

[5] Ajzen, I., Brown, T.C. and Carvajal, F. (2004). "Explaining the discrepancy between intentions and actions: the case of hypothetical bias in contingent valuation." Personality and Social Psychology Bulletin 30, 1108-1121.

[6] Alberini, A., Cropper, M., Krupnick, A. and Simon, N. (2004). "Does the value of a statistical life vary with age and health status? Evidence from the US and Canada." Journal of Environmental Economics and Management, 48, 769-792.

[7] Ash, M., Murphy J. and T. Stevens (2004). "Hypothetical Bias in Dichotomous Choice Contingent Valuation Studies." Department of Economics \&6 Center for Public Policy and Administration University of MassachusettsAmherst, miméo, 11 p.

[8] Bishop, R., and R. T.Woodward. (1995). "Valuation of Environmental Amenities under Certainty." In D.W. Bromley, ed. Handbook of Environmental Economics, 543-67. Oxford: Blackwell Publishers. 
[9] Blumenschein K., Blomquist, G.C., Johannesson, M., Horn, N. and Freeman, P. (2008). "Eliciting willingness to pay without bias: evidence from a field experiment." Economic Journal, 118, 114-137.

[10] Brown, T. C., Azjen, I. and Hrubes, D. (2003). "Further tests of entreaties to avoid hypothetical bias in referendum contingent valuation." Journal of Environmental Economics and Management, 46, 353-361.

[11] Brummett, Robert G., Rodolfo M. Nayga, Jr., and Ximing Wu, (2007) "On the Use of Cheap Talk in New Product Valuation." Economics Bulletin, 2(1), $1-9$.

[12] Bulte, E., Gerking, S., List, J.A. and de Zeeuw, A. (2005). "The Effect of Varying the Causes of Environmental Problems on Stated Values: Evidence from a Field Study." Journal of Environmental Economics and Management, 49(2), 330-342.

[13] Carlsson, F., Frykblom, P. and Lagerkvist, C. J. (2005). "Using cheap talk as a test of validity in choice experiments." Economics Letters, 89, 147-152.

[14] Carlsson F. and Martinsson B. (2006). "Do Experience and Cheap Talk influence Willingness to Pay in an Open-Ended Contingent Valuation Survey?" Working Papers in Economics no. 190, Göteborg University, 18 p.

[15] Chanel, O., Cleary, S., and Luchini, S. (2006). "Does Public Opinion Influence WTP? Evidence from the Field." Applied Economics Letters, 13, 821-824.

[16] Cummings, R. G., Harrison, G. W., and Osborne, L. L. (1995). "Can the Bias of Contingent Valuation Surveys Be Reduced? Evidence from the Laboratory." Economics Working Paper B-95-03, College of Business Administration, University of South Carolina.

[17] Cummings, R. G., and Taylor, L. O. (1999). "Unbiased value estimates for environmental goods: A cheap talk design for the contingent valuation method." American Economic Review, 89(3), 649-666.

[18] Davidson, R., and MacKinnon, J. (1993). Estimation and Inference in Econometrics, Oxford University Press. 
[19] Desaigues, B., Ami D., Hutchison, M., Rabl, A., Chilton S., Metcalf, H., Hunt A., Ortiz R., Navrud S., Kaderjak P., Szanta R., Seested Nielsen J., Jeanrenaud C., Pellegrini S., Braun Kohlova M., Scasny M., ,Maca V., Urban J., Stoeckel M.-E., Bartczak A., Markiewicz O., Riera P., Farreras V. (2007). Final Report on the monetary valuation of mortality and morbidity risks from air pollution, Deliverable D6.7, NEEDS RS1b, February, European Union.

[20] Ehmke, M., J. L. Lusk, and J. List (2008). "Is Hypothetical Bias a Universal Phenomenon? A Multinational Investigation." Land Economics, 84(3), 489500.

[21] Flachaire, E., G. Hollard and S. Luchini (2007). "Heterogeneous anchoring in dichotomous choice valuation framework." Recherches Economiques de Louvain, 73(4), 369-385.

[22] Hausman, J. A. (1993). Contingent Valuation: A Critical Assessment, Contribution to Economic Analysis, Volume 220. New York: North-Holland: J. A. Hausman.

[23] Heckman, J.J. (1979). "Sample Selection Bias as a Specification Error." Econometrica, 47(1), 153-162.

[24] Kennedy, P.E. (1981). "Estimation with correctly interpreted dummy variables in semilogarithmic equations." American Economic Review,71, 801.

[25] Krupnick, A., Alberini, A., Cropper, M., Simon, N., O'Brien, B., Goeree, R., and Heintzelman, M. (2002). "Age, health and the willingness to pay for mortality risk reductions: a contingent valuation study of Ontario residents." Journal of Risk and Uncertainty, 24, 161-186.

[26] Künzli N., Kaiser R., Medina S., Studnicka M., Chanel O., Herry M., Horak F., Puybonnieux-Texier V., Quenel P., Schneider J., Seethaler R., Vergnaud J.-C. and Sommer H. (2000), "Public-health impact of outdoor and trafficrelated air pollution : a European assessment." Lancet, 356:795-801. 
[27] Landry C. and List J. A. (2007). "Using ex ante approaches to obtain credible signals for value in contingent markets: Evidence form the field." American Journal of Agricultural Economics, 89(2); 420-429.

[28] List, J. A. (2001). "Do explicit warnings eliminate the hypothetical bias in elicitation procedures? Evidence from field auction experiments." American Economic Review, 91(5), 1498-1507.

[29] List, J. A. and Gallet C.A. (2001)."What Experimental Protocol Influence Disparities Between Actual and Hypothetical Stated Values? Evidence from a Meta-Analysis." Environmental and Resource Economics, 20, 241-254.

[30] List, J. A., Berrens, R.P., Bohara A.K., and Kerkvliet, J. (2004). "Examining the Role of Social Isolation on Stated Preferences." The American Economic Review, 94(3), 741-752.

[31] List, J. A., Sinha, P., and Taylor M. H. (2006). "Using choice experiments to value non-market goods and services." Advances in Economic Analysis $\mathcal{E}^{6}$ Policy, 6(2), 1-37.

[32] Little J. and Berrens R. (2004). "Explaining Disparities between Actual and Hypothetical Stated Values: Further Investigation Using Meta-Analysis." Economics Bulletin, 3(6), 1-13.

[33] Lusk, J. L. (2003). "Effects of cheap talk on consumer willingness-to-pay for golden rice." American Journal of Agricultural Economics, 85(4), 840-856.

[34] Mitchell, R. C., and R. T. Carson. (1989). Using Surveys to Value Public Goods: The contingent Valuation Method. Resources for the Future., Washington D.C.

[35] Murphy, J. J., Allen, G., Stevens, T. and Weatherhead, D. (2005a). "A MetaAnalysis of Hypothetical Bias in Stated Preference Valuation." Environmental and Resource Economics, 30, 313-325.

[36] Murphy, J. J., Stevens, T. and Weatherhead, D. (2005b). "Is cheap talk effective at eliminating hypothetical bias in a provision point mechanism?" Environmental and Resource Economics, 30(3), 327-343. 
[37] Poe G. L., Clark J. E., Rondeau D. and Schulze, W. D. (2002). "Provision Point Mechanisms and Field Validity Tests of Contingent Valuation." Environmental and Resource Economics, 23, 105-131.

[38] Samnaliev M., Stevens T., and More T. (2003). "A Comparison of Cheap Talk and Alternative Certainty Calibration Techniques in Contingent Valuation." Working Paper No. 2003-11, Department of Resource Economics University of Massachusetts Amherst, $30 \mathrm{p}$.

[39] Viscusi, W., Magat, W.A., and Forrest, A. (1988). "Altruistic and private valuations of risk reduction." Journal of Policy Analysis and Management, 7, $227-245$.

[40] Whitehead, J., and Cherry, T. L. (2007). "Willingness to pay for a Green Energy program: A comparison of ex-ante and ex-post hypothetical bias mitigation approaches" Resource and Energy Economics, 29, 247-261. 


\title{
Notes
}

\begin{abstract}
${ }^{1}$ These methods can be ex-ante or ex-post. Ex-ante approches consist of reminding respondents about the existence of substitutes and/or their budget constraints and consequantialist approaches. Ex-post methods sort answers according to the degree of respondents' self-reported uncertainty or use valuation experiments in the lab to correct CV answers outside the lab.
\end{abstract}

${ }^{2}$ The term cheap talk in the CV literature comes from game theory, where it is defined as a verbal communication (talk) which is costless(cheap), non-binding and non-verifiable .

${ }^{3}$ See for instance Ajzen et al. (2004), Bulte et al. (2005), Carlsson et al. (2005), List et al. (2006) or Landry and List (2007).

${ }^{4}$ This is indeed one of its primary objective as stated for instance in the NOAA's (1993) recommandations.

${ }^{5}$ Note that our approach differs from Alberini et al (2004) and Krupnick et al (2002): when they present the new drug to respondents, they do not refer explicitly to air pollution - the drug is only associated with a reduction in mortality risks.

${ }^{6}$ The air quality in Marseilles, the largest city of the area, was used as a reference situation for all respondents.

${ }^{7}$ Here again, air quality in Marseilles was used as a referent.

${ }^{8}$ Recent studies show that cultural differences may lead to varying hypothetical biases, including no or even negative biases (Ehmke et al., 2008).

${ }^{9}$ Protest responses are when subjects express null WTP and give a reason in closed-ended debriefing questions or open comments that can be described as protests (for instance, "I do not agree with the principle of paying", "I would not pay since I will only move to live in the country", "I do not agree to pay to move to a less polluted place when I can die tomorrow crossing the street" or "I do not want to pay because the factories are the major polluters").

${ }^{10}$ Results obtained in the selection model are clearly equivalent to those obtained with two independent equations.

${ }^{11}$ Due to the limited number of protest responses ( $n=30$ in the initial sample), a specification procedure was use to select a smaller number of covariates in the Probit equation (although we kept all the session and cheap talk dummy variables due to the objective of this study). 
${ }^{12}$ As well as computing the Heckman selection model, we estimated a Box-Cox linear model where the WTP is transformed according to a Box-Cox transformation (see Davidson and McKinnon, 1993). LR tests on the estimated transformation parameter $(\theta=-.0438)$ reject equality to one $(p<.0001)$ or minus one $(p<.0001)$ but cannot reject its nullity $(p=.223)$, that is using the logarithm of the WTP - much easier to handle. In doing so, we however lost some observations - true zero WTP: 12 observations, i.e. $3.2 \%$ of the sample. The model was then estimated by maximum likelihood procedure in Stata 9.0 and $p$-values were computed using the robust variance-covariance matrix (seven other observations were dropped from the analysis due to missing data, mainly on income).

${ }^{13}$ Because the WTP equation is semilogarithmic, the percentage changes in WTP values induced by the petition are computed as per Kennedy (1981).

${ }^{14}$ Based on social psychology findings, List (2001) uses "processing mode" to mean the fact that individuals with strong opinions prior to the valuation exercice are more likely to reject external signals, i.e. invididuals are less sensitive to "the contagious influence of others" (Michelson, 1999, cited by List, 2001).

${ }^{15}$ Note that the approach based on free evocation questions aimed at detecting respondents with stronger opinions in CV surveys may be an interesting way to improve the detection of "experienced" subjects (see Flachaire, Hollard and Luchini 2007). 


\section{A Drug scenario}

You are going to be the main actor in our scenario. You will have to take the best decision for yourself and your household.

Let's imagine that the Ministry of Health has authorized a new drug, different from those currently available. It allows the long-term effects of air pollution exposure to be reduced by half. It simply involves taking a pill every month, which, by the combined action of several vitamins, stimulates immunological responses. It has no side effects and no contra-indications. It can be taken by any person who is more than 5 years old.

This new drug is reimbursed neither by the social security system nor by the $C M U$ (state means-tested health cover) nor by the complementary health insurance policies. This implies that, if you choose to buy it, you will bear the full cost. We would like to know how much you would be willing to pay to use this drug, which would reduce by half the long-term diseases and mortality risks associated with air pollution. Do not forget that this money will be drawn from your household's budget! You will therefore have less money at the end of the month for consumption or savings.

\section{B Move scenario}

You are going to be the main actor in our scenario. You will have to take the best decision for yourself and your household.

Let's imagine that you and your household have to move. You can choose between two cities which are exactly equivalent in terms of inhabitants, working conditions, schools, climate, public services, cultural life, transport, housing, surroundings, etc. There is only one difference between them: the level of atmospheric pollution. The first city - let's call it POL - is as polluted as Marseilles. And the second city - let's call it LESSPOL - is half as polluted as Marseilles. 
The problem is that the cost of living is higher in LESSPOL (the less polluted city): housing, local taxes, public transport, etc. are more expensive. This means that if you choose to move to LESSPOL, you will have to pay more to have the same standard of living as in POL.

We would like to know how much you would be willing to pay per month for you and your household to move to LESSPOL (the less polluted city) rather than to POL (the town as polluted as Marseilles). Do not forget that this money will be drawn from your household's budget! You will therefore have less money at the end of the month for consumption and savings.

\section{Regulation scenario}

You are going to be the main actor in our scenario. You will have to take the best decision for yourself and your household.

Let's imagine that new laws and rules are to be adopted to limit air pollution. Therefore industries, manufacturers of consumer products, public or private transport, will have to adopt less polluting technologies. Studies have shown that these new laws and rules will make it possible to reduce by half the number of highly polluted days in the PACA region, and particularly in Marseilles.

The implementation of these new technologies will induce higher costs in everyday life: energy, food and other goods, transport. This means that you will have to pay more to enjoy the same standard of living as before the implementation of these new laws and rules.

We would like to know how much you would be willing to pay per month for these new laws and rules to be implemented. Do not forget that this money will be drawn from your household's budget! You will therefore have less money at the end of the month for consumption and savings. 


\section{Cheap Talk script}

Similar studies show that the amount subjects are willing to pay can differ from what they would pay in real life.

For instance, some subjects state a lower willingness to pay in relation to what they would otherwise pay, or even refuse to pay anything. This could be explained by the fact that they want to express a point of view such as "I have the right to breathe good quality air" or "I shouldn't have to pay for good quality air; it's polluting firms or the state who should pay".

On the other hand, people may state a higher amount than they would pay in real life, that is, if they really had to pay out of their pockets.

We would like you to try not to behave like these people, but to answer as sincerely as possible.

If you want to make any comments concerning the amount of money you state which you didn't have the opportunity to verbalize during the procedure, don't hesitate to write them down at the end of the questionnaire, where a space is devoted to your comments. 


\section{E Sample descriptive Statistics}

\begin{tabular}{|c|c|c|c|}
\hline Variable & Description & Mean & (sd) \\
\hline $\log ($ Indinc $)$ & $\begin{array}{l}\text { Logarithm of Monthly individual } \\
\text { income (euros) }\end{array}$ & 6.974 & $(.765)$ \\
\hline Male & Subject is male $(=1)$ & .349 & $(.477)$ \\
\hline Age & Age of the subject (years) & 39.7 & $(14.19)$ \\
\hline$H S E d u$ & Senior High School Education $(=1)$ & .163 & $(.370)$ \\
\hline UnivEdu & University level Education (=1) & .362 & $(.481)$ \\
\hline Owner & $\begin{array}{l}\text { Status of the occupant of the } \\
\text { place of residence }(=1)\end{array}$ & .465 & $(.499)$ \\
\hline LivMars & Subject lives in Marseilles $(=1)$ & .752 & $(.432)$ \\
\hline EnvPresAss & $\begin{array}{l}\text { Subject belongs to an environmental } \\
\text { preservation association }(=1)\end{array}$ & .489 & $(.050)$ \\
\hline PrivIns & $\begin{array}{l}\text { Subject has private health } \\
\text { insurance }(=1)\end{array}$ & .819 & $(.384)$ \\
\hline Marsgood & $\begin{array}{l}\text { Subject says that the air quality in } \\
\text { Marseilles is good or very good }(=1)\end{array}$ & .059 & $(.236)$ \\
\hline HealthWork & Subject is a health worker $(=1)$ & .537 & $(.225)$ \\
\hline ChangHab & $\begin{array}{l}\text { Subject changes habits during } \\
\text { highly polluted days }(=1)\end{array}$ & .580 & $(.494)$ \\
\hline FreshAir & $\begin{array}{l}\text { Subject regularly goes to } \\
\text { countryside to breathe fresh air }(=1)\end{array}$ & .798 & $(.401)$ \\
\hline RespolT & $\begin{array}{l}\text { Subject has personally felt the effects } \\
\text { of air pollution }(=1)\end{array}$ & .53 & $(.225)$ \\
\hline NevSortWaste & Subject never sorts his/her waste $(=1)$ & .209 & $(.407)$ \\
\hline Unlucky & $\begin{array}{l}\text { Subject considers him/herself unlucky } \\
\text { in everyday life on average }(=1)\end{array}$ & .134 & $(.341)$ \\
\hline KnowPol & $\begin{array}{l}\text { Subject declares a good } \\
\text { knowledge of air pollution }(=1)\end{array}$ & .241 & $(.428)$ \\
\hline KnowAirmaraix & $\begin{array}{l}\text { Subject knows the AIRMARAIX local } \\
\text { air pollution index }(=1)\end{array}$ & .239 & $(.427)$ \\
\hline KnowAtmo & $\begin{array}{l}\text { Subject knows the ATMO official scale } \\
\text { of air pollution levels }(=1)\end{array}$ & .231 & $(.422)$ \\
\hline
\end{tabular}

$(N=372)$ 


\begin{tabular}{|c|c|c|}
\hline Variable & $\begin{array}{l}\text { Estimated } \\
\text { parameter }\end{array}$ & $\begin{array}{r}\text { Robust } \\
p-\text { value }\end{array}$ \\
\hline \multicolumn{3}{|l|}{ Individual's characteristics } \\
\hline Constant & .016 & 0.980 \\
\hline Log(Indinc) & .250 & 0.005 \\
\hline Male & .191 & 0.114 \\
\hline Age & .005 & 0.263 \\
\hline HSEdu & .036 & 0.828 \\
\hline UnivEdu & .522 & 0.000 \\
\hline Owner & -.167 & 0.217 \\
\hline LivMars & -.093 & 0.488 \\
\hline EnvPresAss & .180 & 0.137 \\
\hline PrivIns & .33 & 0.069 \\
\hline Marsgood & -.049 & 0.848 \\
\hline HealthWork & .310 & 0.179 \\
\hline ChangHab & .120 & 0.305 \\
\hline FreshAir & .27 & 0.120 \\
\hline ResPolT & .530 & 0.134 \\
\hline NevSortWaste & -.302 & 0.041 \\
\hline Inlucky & -.245 & 0.150 \\
\hline \multicolumn{3}{|l|}{ Experience effects } \\
\hline KnowPol & -.271 & 0.218 \\
\hline KnowAirmaraix & -.249 & 0.234 \\
\hline KnowAtmo & .178 & 0.396 \\
\hline \multicolumn{3}{|l|}{ Scenario effects } \\
\hline Move & 1.300 & 0.000 \\
\hline Regulation & .2509 & 0.298 \\
\hline \multicolumn{3}{|l|}{ Cheap talk effects } \\
\hline Drug $\times$ cheap talk & -.099 & 0.725 \\
\hline Move $\times$ cheap talk & -.498 & 0.048 \\
\hline Regulation $\times$ cheap talk & -.628 & 0.001 \\
\hline \multicolumn{3}{|c|}{ Experience and cheap talk effects } \\
\hline KnowPol $\times$ cheap talk & .283 & 0.382 \\
\hline KnowAtmo $\times$ cheap talk & .210 & 0.501 \\
\hline KnowAirmaraix $\times$ cheap talk & .056 & 0.851 \\
\hline
\end{tabular}

Fisher joint nullity test: $\mathrm{F}(28,282)=10.02, p=0.0000$

Table 4: $\log (\mathrm{WTP})$ equation $(N=311)$ 